\section{EFFECT OF SURGERY ON RESTING CALF BLOOD FLOW}

\author{
BY
}

N. L. BROWSE, M.D., F.R.C.S.

Department of Surgery, University of Bristol*

The rate at which blood flows through the muscle of the calf is a matter of concern to both physicians and surgeons, for all accept that anything effecting a reduction in flow may increase the likelihood of spontaneous intravascular thrombosis and pulmonary embolism.

Because surgical operations are not infrequently followed by deep-vein thrombosis a number of workers have studied the effect of surgery upon the rate of blood flow in the leg veins to see if it is followed by any reduction of flow (Smith and Allen, 1940 ; Wright et al., 1948). Flow through the veins depends primarily upon

\section{Subjects}

Forty-five patients have been studied. They were chosen at random, except for their sex. The problem of finding a chaperon in a busy female ward made it difficult to study many women. Once it was found that changes identical to those already observed in men occurred in the first three women studied (Cases 14, 26 , and 39), it was decided that sex was not significant and the remainder of the studies were made on men.

The first 30 patients (group 1) were studied solely to elicit the effect of surgery upon their calf blood flow. The next 15 (group 2) were given various drugs once the nature of their response to surgery became obvious. These drugs may have altered the duration of the response, and so it comes about that the figures for the nature, incidence, and extent of the response are drawn from all 45 patients (both groups), but those concerning the duration of the response are derived from group 1.

TABLE I.-Details of Subjects 1-30 (Group 1)

\begin{tabular}{|c|c|c|c|c|c|c|c|c|c|c|c|c|c|c|c|}
\hline Case No. : & 1 & 2 & 3 & 4 & 5 & 6 & 7 & 8 & 9 & 10 & 11 & 12 & 13 & 14 & 15 \\
\hline 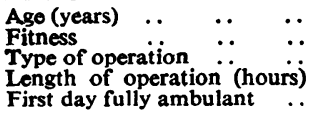 & $\begin{array}{r}24 \\
\mathbf{A} \\
\mathbf{H} \\
\frac{1}{4}\end{array}$ & $\begin{array}{r}30 \\
\mathbf{B} \\
\mathbf{H} \\
\frac{1}{5}\end{array}$ & $\begin{array}{r}27 \\
\mathbf{A} \\
\mathbf{H} \\
\frac{8}{4} \\
4\end{array}$ & $\begin{array}{l}56 \\
\text { B } \\
\text { UA } \\
1 \frac{1}{2} \\
6\end{array}$ & $\begin{array}{c}55 \\
\mathbf{C} \\
\mathbf{L A} \\
1 \\
4\end{array}$ & $\begin{array}{r}43 \\
\mathbf{B} \\
\mathbf{H} \\
\frac{8}{2} \\
2\end{array}$ & $\begin{array}{c}74 \\
\mathbf{C} \\
\mathbf{H} \\
6 \\
6\end{array}$ & $\begin{array}{c}61 \\
\mathbf{L A} \\
1 \\
5\end{array}$ & $\begin{array}{r}63 \\
\mathrm{~B} \\
\mathrm{H} \\
2 \\
8\end{array}$ & $\begin{array}{c}75 \\
\text { B } \\
\text { LA } \\
\frac{3}{2} \\
4\end{array}$ & $\begin{array}{c}62 \\
\text { B } \\
\text { LA } \\
2 \\
9\end{array}$ & $\begin{array}{l}72 \\
\text { UA } \\
2 \\
6\end{array}$ & $\begin{array}{l}49 \\
\text { B } \\
\text { UA } \\
1 \frac{1}{2} \\
7\end{array}$ & $\begin{array}{c}64 \\
\mathbf{B} \\
\mathbf{M} \\
1 \frac{1}{2}\end{array}$ & $\begin{array}{c}19 \\
\mathbf{A} \\
\mathbf{L A} \\
\frac{1}{8}\end{array}$ \\
\hline
\end{tabular}

TABLE I.-continued

\begin{tabular}{|c|c|c|c|c|c|c|c|c|c|c|c|c|c|c|c|}
\hline Case No. : & 16 & 17 & 18 & 19 & 20 & 21 & 22 & 23 & 24 & 25 & 26 & 27 & 28 & 29 & 30 \\
\hline 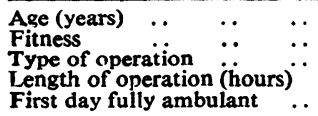 & $\begin{array}{c}35 \\
\text { B } \\
\text { UA } \\
1 \frac{1}{2} \\
7\end{array}$ & $\begin{array}{r}33 \\
\mathbf{A} \\
\mathbf{H} \\
\frac{4}{5} \\
5\end{array}$ & $\begin{array}{c}\mathbf{5 3} \\
\mathbf{B} \\
\mathbf{H} \\
\frac{\mathbf{t}}{3} \\
\mathbf{3}\end{array}$ & 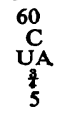 & $\begin{array}{l}\mathbf{6 5} \\
\mathbf{U A} \\
2 \frac{1}{2} \\
10\end{array}$ & $\begin{array}{r}\mathbf{3 4} \\
\mathbf{A} \\
\mathbf{P} \\
\frac{1}{2} \\
\mathbf{1}\end{array}$ & $\begin{array}{c}32 \\
\mathbf{A} \\
\mathbf{H} \\
\frac{1}{2} \\
5\end{array}$ & $\begin{array}{r}64 \\
\mathbf{B} \\
\mathbf{H} \\
\frac{3}{4} \\
4\end{array}$ & $\begin{array}{c}51 \\
\mathbf{B} \\
\mathbf{H} \\
\frac{8}{4} \\
4\end{array}$ & $\begin{array}{c}54 \\
\mathrm{~B} \\
\mathrm{H} \\
\frac{3}{5}\end{array}$ & $\begin{array}{c}55 \\
\mathbf{B} \\
\mathbf{M} \\
2 \\
9\end{array}$ & $\begin{array}{c}28 \\
\mathbf{A} \\
\mathbf{L A} \\
\frac{1}{2} \\
4\end{array}$ & $\begin{array}{c}51 \\
B \\
\mathrm{VV} \\
\frac{3}{2} \\
2\end{array}$ & $\begin{array}{l}25 \\
\text { id } \\
\mathrm{VV} \\
\frac{9}{2} \\
2\end{array}$ & $\begin{array}{l}49 \\
\text { B } \\
\mathrm{VV} \\
1 \\
4\end{array}$ \\
\hline
\end{tabular}

$\mathbf{H}=$ Herniorrhaphy. UA $=$ Upper abdominal. $\mathbf{L A}=$ Lower abdominal. $\quad \mathbf{M}=$ Radical mastectomy. $\quad \mathrm{VV}=$ Varicose veins (stripping). $\mathbf{P}=\mathbf{\text { Haemor }}$ rhoidectomy. $\mathbf{F}=$ Parotidectomy. $\mathrm{T}=$ Thyroidectomy.

TABLE II.-Details of Subjects 31-45 (Group 2)

\begin{tabular}{|c|c|c|c|c|c|c|c|c|c|c|c|c|c|c|c|}
\hline Case No. : & 31 & 32 & 33 & 34 & 35 & 36 & 37 & 33 & 39 & 40 & 41 & 42 & 43 & 44 & 45 \\
\hline $\begin{array}{llll}\text { Age (years) } & \ldots & \ldots & \ldots \\
\text { Fitness } & \ldots & \ldots \\
\text { Type of operation } & \cdots & \\
\text { Length of operation (hours) } \\
\text { First day fully ambulant }\end{array}$ & $\begin{array}{c}55 \\
\text { B } \\
\text { UA } \\
2 \\
4\end{array}$ & $\begin{array}{r}74 \\
\mathbf{H} \\
1 \frac{1}{2} \\
5\end{array}$ & $\begin{array}{c}35 \\
-B \\
\mathbf{H} \\
\stackrel{8}{t} \\
4\end{array}$ & $\begin{array}{r}30 \\
\mathbf{B} \\
\mathbf{H} \\
\frac{3}{3} \\
4\end{array}$ & $\begin{array}{r}48 \\
\mathrm{~B} \\
\mathrm{~F} \\
1 \frac{1}{3} \\
3\end{array}$ & $\begin{array}{c}66 \\
\mathbf{B} \\
\stackrel{4}{H} \\
1 \\
4\end{array}$ & $\begin{array}{c}\text { 59 } \\
\text { B } \\
\text { UA } \\
\frac{1}{2} \\
3\end{array}$ & $\begin{array}{r}20 \\
\mathbf{A} \\
\mathbf{H} \\
8 \\
\frac{8}{4} \\
4\end{array}$ & $\begin{array}{r}38 \\
\mathbf{B} \\
\mathbf{T} \\
1 \frac{1}{2} \\
5\end{array}$ & $\begin{array}{c}34 \\
\mathbf{B} \\
\mathbf{H} \\
\frac{3}{2} \\
4\end{array}$ & $\begin{array}{c}33 \\
\mathbf{A} \\
\mathbf{H} \\
\frac{1}{2} \\
4\end{array}$ & $\begin{array}{c}\mathbf{6 6} \\
\underset{\mathrm{H}}{\mathrm{H}} \\
\frac{a}{3} \\
3\end{array}$ & $\begin{array}{c}42 \\
\mathbf{C} \\
\mathbf{U A} \\
11 \\
7\end{array}$ & $\begin{array}{l}59 \\
\text { B } \\
U_{A} \\
1 \frac{1}{2} \\
7\end{array}$ & $\begin{array}{c}17 \\
\mathbf{A} \\
\mathbf{H} \\
2 \\
4\end{array}$ \\
\hline
\end{tabular}

arterial flow. It is surprising that there are no studies of the effect of surgery upon this inflow to the calf in the major medical journals. This paper fills that gap in our knowledge. Briefly, it shows that $75 \%$ of patients who undergo surgical operations have a marked diminution of their calf blood flow for the subsequent six to eight days; the other $25 \%$ have a rise in flow. This may be an important and significant observation, but an attempt is here made only to describe, document, and entitle it the "circulatory response to surgery."

Technique. - The method of venous-occlusion plethysmography used in these experiments is described in the paper which follows this (Browse, 1962). Any change in flow greater than $20 \%$ is regarded as significant and is interpreted as a change of muscle blood flow. Each patient acts as his own control and his response is assessed individually.

*Now Lecturer in Surgery, Westminster Hospital.
Tables I and II summarize the clinical features of the patients, the type and duration of their operations, and record the day of return to full activity.

Age.-Patients of all ages were studied (17-75 years). The two under 20 (Cases 15 and 45) are included for simplicity in the 20-39 age-group. In group 1 the age distribution is even, but in group 2 there is a preponderance of young men. Overall, the random selection has produced a fairly even distribution of ages.

Fitness.-To assess the effect of a patient's fitness upon his response it was necessary to make a fitness classification. Three grades were made:

Class $A$, the above average, athletically fit man. This usually applied only to the younger group.

Class $B$, the average man not suffering from any illness, able to perform a day's heavy work but not exceptionally fit to the extent of being able to play a game of squash or rugby with ease. 
Class $C$, the unfit patient. Those with cardiac or pulmonary disease, those suffering from the effects of the disease for which they had been admitted (for example, loss of weight and malaise due to carcinoma), or those not fit enough to perform their normal day's work.

Most patients come into class B. There is a slightly higher incidence of young men in the series, so there are more class $A$ patients than class $C$.

Type of Operation Performed.-The series contains all types of operation. They are grouped together under four headings: Abdominal (16) includes gastrectomy ( 2 cases), vagotomy and gastroenterostomy (4), upper abdominal laparotomy for carcinoma (2), cholecystectomy (1), appendicectomy (3), retropubic prostatectomy (2), synchronous combined excision of rectum (1), Heller's operation (1). Hernia (21) means inguinal or femoral herniorrhaphy. Varicose veins (3) means unilateral sapheno-femoral ligation and stripping. Others (5) include radical mastectomy (2), parotidectomy (1), thyroidectomy (1), haemorrhoidectomy (1).

Later on the types of operation are divided into abdominal and others. It was apparent that the abdominal cases suffered far more surgical trauma, shock, and post-operative pain than the rest, and so they are compared with the remainder in order to assess the effect of the magnitude of the operation upon the type and nature of the response.

Length of Operation.-The various operations took from a half to $2 \frac{1}{2}$ hours to perform. For comparison they are divided into two groups: short, up to $1 \frac{1}{4}$ hours ; and long, $1 \frac{1}{2}$ hours or more.
Immediate Post-operative Condition.-After operation Cases 11, 12, 14, and 20 had periods of mild hypotension varying from two to six hours.

Post-operative Activity.-Each patient kept a record of the time he spent out of bed each day after operation. It was found that once a patient was allowed up for five hours he was fully ambulant (Tables I and II), and thereafter spent most of his day up and about.

\section{Results}

Table III gives the results of the daily measurements of the resting calf blood flow. The -0 column indicates readings taken one or two hours before operation. It was not always possible to take a measurement from each patient every day, hence the occasional gaps in the series. Flows were measured until they had returned to the pre-operative level or until the patient was discharged. Each patient's temperature, pulse rate, and blood-pressure were recorded daily (Browse, 1961).

Temperature.-A number of patients had a mild post-operative pyrexia. One (Case 15) had a remittent temperature above $100^{\circ} \mathrm{F}$. $\left(37.8^{\circ} \mathrm{C}\right.$.) for four days. Pyrexia did not appear to affect the calf blood flow in any case.

Tachycardia.-No patient had any change in pulse rate beyond physiological limits.

Blood-pressure.-No significant change in bloodpressure was observed apart from the periods of hypotension that followed operation in Cases 11, 12, 14 , and 20.

\section{Analysis}

When the figures of Table III are plotted graphically it can be seen that three changes in calf blood flow may

TABLE III.-Results of Daily Measurements of Calf Blood Flow

\begin{tabular}{|c|c|c|c|c|c|c|c|c|c|c|c|c|c|c|c|c|c|c|c|}
\hline \multirow{2}{*}{$\begin{array}{l}\text { Case } \\
\text { No. }\end{array}$} & \multicolumn{19}{|c|}{$\begin{array}{l}\text { Resting Calf Blood Flow' (m1./min. } / 100 \mathrm{ml} \text {. Tissue) } \\
\text { Days Before and After Operation }\end{array}$} \\
\hline & -3 & -2 & -1 & -0 & 1 & 2 & 3 & 4 & 5 & 6 & 7 & 8 & 9 & 10 & 11 & 12 & 13 & 14 & 15 \\
\hline $\begin{array}{c}1 \\
2 \\
3 \\
4 \\
5 \\
6 \\
7 \\
8 \\
9 \\
10 \\
11 \\
12 \\
13 \\
14 \\
15 \\
16 \\
17 \\
18 \\
19 \\
20 \\
21 \\
22 \\
23 \\
24 \\
25 \\
26 \\
27 \\
29 \\
29 \\
30\end{array}$ & $\begin{array}{l}1.5 \\
1.7\end{array}$ & $\begin{array}{l}1.6 \\
1.9\end{array}$ & 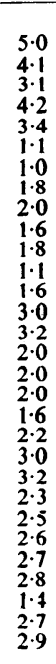 & $\begin{array}{l}3.3 \\
2.1 \\
1.8 \\
\\
3.3 \\
2.4 \\
2.6 \\
\\
1.4 \\
2.7 \\
2.9\end{array}$ & $\begin{array}{l}2.0 \\
2.3 \\
2.7 \\
2.4 \\
0.9 \\
0.9 \\
0.7 \\
0.6 \\
4.2 \\
1.2 \\
0.6 \\
0.5 \\
4.1 \\
2.1 \\
1.6 \\
1.6 \\
3.2 \\
3.7 \\
1.9 \\
1.2 \\
4.3 \\
1.9 \\
1.4 \\
2.5 \\
2.0 \\
1.7 \\
1.3 \\
1.8 \\
1.9 \\
2.3\end{array}$ & $\begin{array}{l}2.2 \\
2.5 \\
2.0 \\
1.5 \\
0.7 \\
0.4 \\
0.3 \\
1.2 \\
6.8 \\
1.4 \\
0.4 \\
0.6 \\
2.2 \\
2.0 \\
1.7 \\
2.0 \\
2.7 \\
\\
1.4 \\
3.6 \\
1.6 \\
1.5 \\
2.3 \\
7 \\
1.4 \\
1.5 \\
2.3 \\
2.1\end{array}$ & $\begin{array}{l}4.5 \\
3.0 \\
2.1 \\
1.6 \\
1.1 \\
= \\
\\
2.7 \\
0.5 \\
0.4 \\
1.8 \\
1.9 \\
1.6 \\
1.7 \\
2.4 \\
1.7 \\
2.0 \\
1.6 \\
1.9 \\
1.9 \\
1.8 \\
1.5 \\
1.1 \\
2.4 \\
2.2\end{array}$ & $\begin{array}{l}G . \\
3.5 \\
3.5 \\
2.3 \\
2.0 \\
1.4 \\
0.6 \\
0.5 \\
1.5 \\
- \\
0.6 \\
0.7 \\
1.4 \\
1.6 \\
1.3 \\
3.4 \\
1.6 \\
1.8 \\
2.8 \\
1.8 \\
2.7 \\
2.6 \\
1.8 \\
0.6 \\
1.7\end{array}$ & 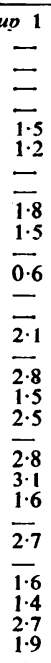 & $\begin{array}{l}4.5 \\
4.1 \\
3.0 \\
4.0 \\
1.3 \\
1.2 \\
2.5 \\
1.2 \\
0.7 \\
0.8 \\
1.5 \\
1.3 \\
\overline{2} \\
2.7 \\
7 \\
1.7 \\
2.9 \\
= \\
2.6 \\
3.0 \\
2.2 \\
2.2 \\
= \\
-\end{array}$ & 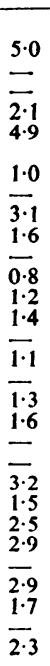 & $\begin{array}{l}4.0 \\
2.9 \\
= \\
1.0 \\
1.5 \\
2.7 \\
0.8 \\
\overline{1.2} \\
\frac{-2.5}{0.7} \\
2.8 \\
\bar{Z} \\
2.8 \\
-\overline{2.6} \\
2.5 \\
\overline{2.7}\end{array}$ & $\begin{array}{l}\frac{1.0}{2} \\
\frac{2 \cdot 0}{二} \\
= \\
\overline{2 \cdot 0} \\
1.7 \\
- \\
1.4\end{array}$ & $\begin{array}{l}1.9 \\
1.2 \\
1.4 \\
1.6 \\
3.1 \\
1.0 \\
2.3 \\
1.7 \\
2.2 \\
- \\
\\
3.0 \\
-\end{array}$ & $\begin{array}{l}\overline{1.2} \\
\overline{3.2} \\
\overline{-} \\
- \\
1.9\end{array}$ & $\begin{array}{l}\frac{1 \cdot 7}{1 \cdot 1} \\
\frac{2.0}{T} \\
\frac{1.3}{2.0} \\
2.2 \\
-\end{array}$ & $\frac{1 \cdot 6}{3 \cdot 4}$ & $\frac{2 \cdot 4}{2 \cdot 2}$ & $\begin{array}{l}2 \cdot 6 \\
3 \cdot 1\end{array}$ \\
\hline $\begin{array}{l}31 \\
32 \\
33 \\
34 \\
35 \\
36 \\
37 \\
38 \\
39 \\
40 \\
41 \\
42 \\
43 \\
44 \\
45\end{array}$ & $\begin{array}{l}1.8 \\
1 \cdot 3\end{array}$ & $\begin{array}{l}1.8 \\
2.6 \\
1.8\end{array}$ & $\begin{array}{l}1.8 \\
1.0 \\
2.8 \\
2.2 \\
1.0 \\
2.0 \\
1.8 \\
2.2 \\
1.6 \\
3.6 \\
3.4 \\
1.8 \\
1.2 \\
2.5 \\
2.0\end{array}$ & $\begin{array}{l}2.8 \\
2.1 \\
3.6\end{array}$ & $\begin{array}{l}2.2 \\
0.6 \\
2.8 \\
1.8 \\
1.5 \\
2.5 \\
4.8 \\
1.5 \\
1.0 \\
3.5 \\
1.9 \\
2.2 \\
0.9 \\
1.6 \\
1.3\end{array}$ & $\begin{array}{l}1.2 \\
0.3 \\
1.8 \\
1.1 \\
1.0 \\
2.3 \\
2.2 \\
1.8 \\
1.0 \\
2.5 \\
2.6 \\
2.0 \\
\frac{7}{1.3}\end{array}$ & $\begin{array}{l}1.0 \\
\bar{Z} \\
2.3 \\
2.1 \\
1.4 \\
1.7 \\
1.9 \\
1.1 \\
= \\
\bar{Z} \\
0.9 \\
1.7 \\
1.6\end{array}$ & $\begin{array}{l}\text { Gro } \\
0.8 \\
0.6 \\
2.5 \\
1.8 \\
1.9 \\
1.7 \\
1.8 \\
1.6 \\
2.9 \\
1.5 \\
1.7 \\
1.6 \\
\end{array}$ & $\begin{array}{l}1.0 \\
1.2 \\
2.0 \\
2.0 \\
1.3 \\
1.8 \\
=\end{array}$ & $\begin{array}{l}\overline{\overline{2}} \\
1 \cdot 7 \\
1 \cdot 7 \\
\overline{\frac{1}{2 \cdot 3}}\end{array}$ & $\begin{array}{l}1 \cdot 2 \\
1 \cdot 0 \\
1 \cdot 6 \\
2 \cdot 0 \\
2.0 \\
1 \cdot 8 \\
2.1 \\
1.6\end{array}$ & $\begin{array}{l}- \\
1.7 \\
2.4\end{array}$ & $\begin{array}{l}2 \cdot 0 \\
-\overline{2 \cdot 1}\end{array}$ & - & $\begin{array}{l}1 \cdot 7 \\
1\end{array}$ & $2 \cdot 3$ & $\cdots$ & & \\
\hline
\end{tabular}


follow surgery. The rate of flow may fall, or rise, or rise and fall. Furthermore, the fall or rise can be immediate or gradual. To analyse these changes they have been named and defined thus:

\section{Definitions}

Type 1.-Those cases that show a fall in rate of blood flow. Subdivided into: IA, those in which the fall is present on the first day following operation (Fig. 1) ; IB, those in which the fall begins after the first day after operation (Fig. 2).

Type 11.-Those cases that show a rise in rate of blood flow. Subdivided into: IIA, those in which the
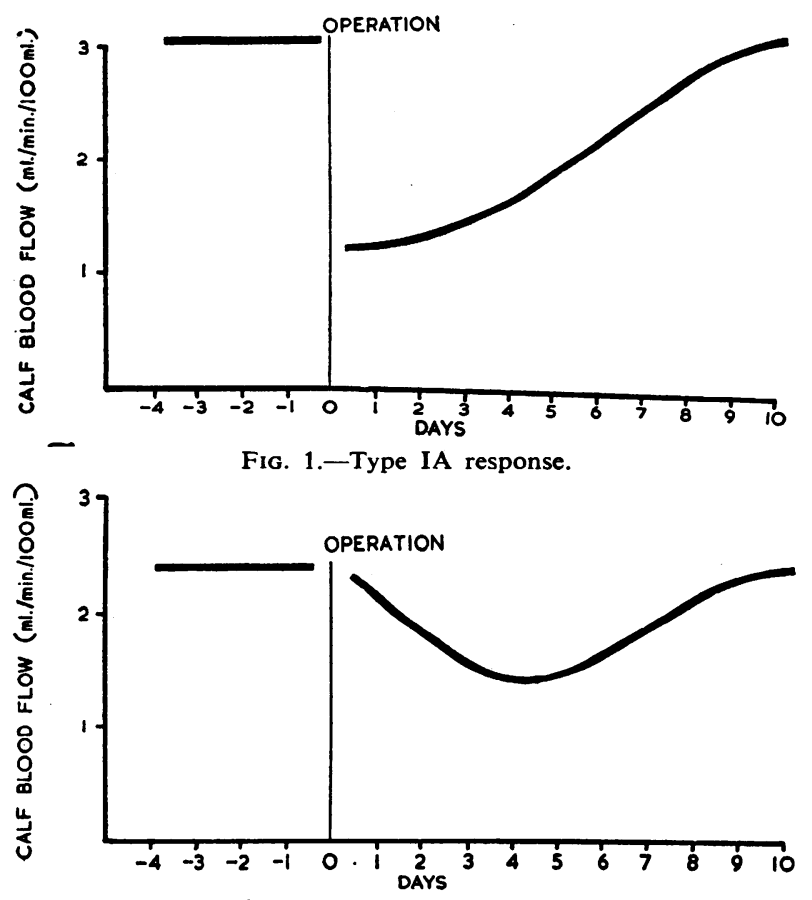

FIG. 2.-Type IB response. rise is present on the first day after operation (Fig. 3) ; IIB, those in which the rise begins after the first day following operation (Fig. 4).

Type III.-Those cases that show a rise in flow on first day after operation followed by a fall to a level below that recorded before operation (Fig. 5).

Table IV shows which type of change occurred in each patient, together with its extent and duration.

The incidence of the three types of response was type I, 34 cases (24 in IA and 10 in IB) (75.5\%); type II,

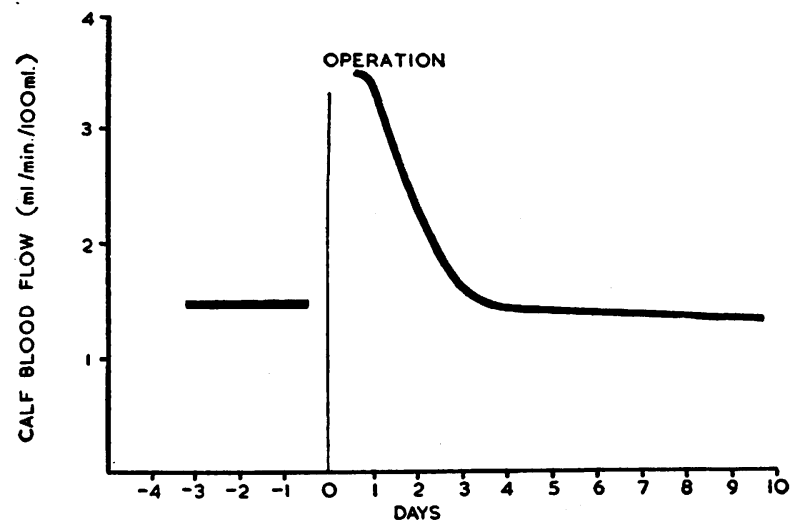

Fig. 3.-Type IIA response.

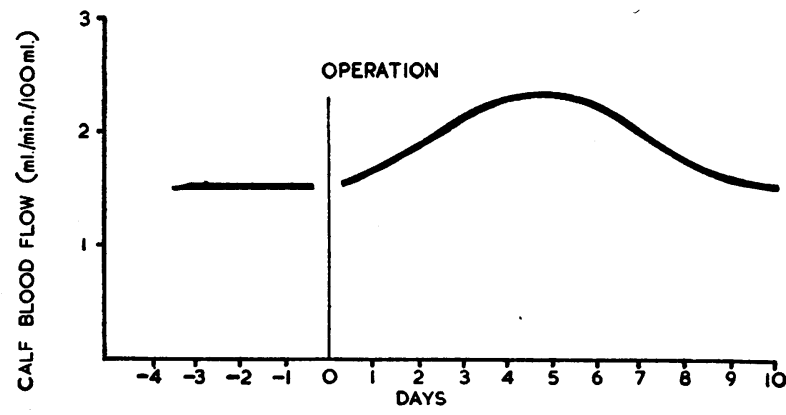

FIG. 4.-Type IIB response

TABLE IV.-Main Features of Changes in Blood Flow

\begin{tabular}{c|c|c|c|c|c|c|c|c|c|c|c|c|c|c|c}
\hline Case No. : & 1 & 2 & 3 & 4 & 5 & 6 & 7 & 8 & 9 & 10 & 11 & 12 & 13 & 14 & 15 \\
\hline Type of change & IA & IA & IB & IA & IA & IB & IB & IA & III & IA & IA & IA & IIA & IA & IA \\
$\begin{array}{c}\text { Extent of change } \\
\text { \% pre-op. level }:\end{array}$ & -60 & -44 & -35 & -64 & -80 & -58 & -66 & -66 & $+\underline{220}$ & -25 & -75 & -65 & +150 & -58 & -49 \\
$\begin{array}{c}\text { Duration of } \\
\text { change (days) }\end{array}$ & 6 & 5 & 5 & 15 & 6 & 4 & 4 & 6 & $\frac{3}{6}$ & 6 & 12 & 8 & 3 & 15 & 12 \\
\hline
\end{tabular}

TABLE IV.-continued

\begin{tabular}{|c|c|c|c|c|c|c|c|c|c|c|c|c|c|c|c|}
\hline Case No. : & 16 & 17 & 18 & 19 & 20 & 21 & 22 & 23 & 24 & 25 & 26 & 27 & 28 & 29 & 30 \\
\hline Type of change & IB & IIA & III & IIB & IA & IIA & IA & IA & IB & IA & IA & IA & III & IA & IA \\
\hline $\begin{array}{l}\text { Extent of change } \\
\text { (\% pre-op. level) }\end{array}$ & -65 & +65 & $\begin{array}{l}+95 \\
-31\end{array}$ & +56 & -45 & +43 & -48 & -39 & -24 & -26 & -37 & -52 & $\begin{array}{l}+28 \\
-57\end{array}$ & -31 & -40 \\
\hline $\begin{array}{l}\text { Duration of } \\
\text { change (days) }\end{array}$ & 15 & 9 & $\frac{2}{11}$ & 6 & 9 & 3 & 4 & 13 & 3 & 3 & 8 & 7 & $\frac{1}{4}$ & 4 & 10 \\
\hline
\end{tabular}

TABLE IV.-continued

\begin{tabular}{|c|c|c|c|c|c|c|c|c|c|c|c|c|c|c|c|}
\hline Case No. : & 31 & 32 & 33 & 34 & 35 & 36 & 37 & 38 & 39 & 40 & 41 & 42 & 43 & 44 & 45 \\
\hline Type of change & IB & IB & IB & IB & IIA & III & IIA & IA & IA & IB & IA & IIA & IA & IA & IA \\
\hline $\begin{array}{l}\text { Extent of change } \\
\text { (\% \%re-op. level) }\end{array}$ & -54 & -66 & -36 & -50 & +50 & $\begin{array}{l}+25 \\
-30\end{array}$ & +166 & -32 & -37 & -30 & -44 & +20 & -25 & -38 & -35 \\
\hline $\begin{array}{l}\text { Duration of } \\
\text { change (days) }\end{array}$ & ? & ? & ? & $?$ & 1 & $\frac{2}{3}$ & 2 & $?$ & ? & $?$ & ? & 2 & $?$ & ? & $?$ \\
\hline
\end{tabular}

$+=$ Rise in flow. $\quad-=$ Fall in flow. Type III patients have double figures - the upper for the rise and the lower for the fall. 
7 cases (6 in IIA and 1 in IIB) $(15.5 \%)$; and type III, 4 cases $(9 \%)$.

A drop in flow was the commonest response. Twothirds of the type I patients showed an immediate drop in flow and one-third a gradual drop. Type IIB response was the least common.

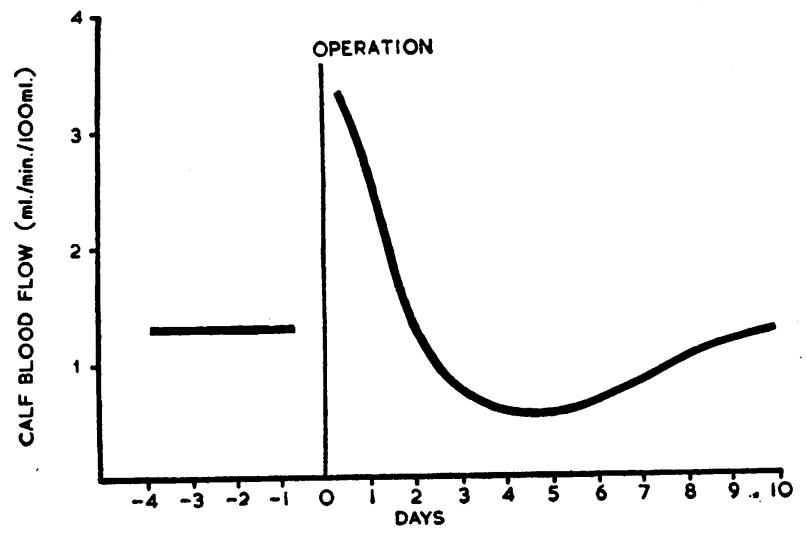

Fig. 5.-Type III response.

\section{Analysis of Those Factors Likely to Affect Type of Response}

Seven things are known about each patient-age, fitness, type of operation, length of operation, nature of the anaesthetic, immediate post-operative state, and post-operative activity. The possible effect of each of these on the incidence of the type of response is examined.

Age.-The distribution of cases in each column of Table $\mathrm{V}$ is the same as the overall incidence of the three types; there is nothing to suggest that age has any effect on the type of response.

Fitness.-The distribution in Table VI is the same as the overall distribution of each response and each class of fitness. Fitness does not affect the type of response.

Type of Operation.-Table VII shows that the type of operation performed does not affect the type of response.

Length of Operation.-Table VIII contains fewer cases of the type II and III response in the $1 \frac{1}{2}-2 \frac{1}{2}$ hour group than expected. This may mean that the shorter

\begin{tabular}{|c|c|c|c|}
\hline \multirow{2}{*}{$\begin{array}{c}\text { Type } \\
\text { of } \\
\text { Response }\end{array}$} & \multicolumn{3}{|c|}{ Age (Years) } \\
\hline & $20-39$ & $40-59$ & $60-79$ \\
\hline II & $\begin{array}{r}16 \\
2\end{array}$ & $\begin{array}{r}10 \\
3 \\
2\end{array}$ & $\begin{array}{l}8 \\
2 \\
2\end{array}$ \\
\hline
\end{tabular}

TABLE VI.-Relationship Between Fitness and Type of Response

\begin{tabular}{c|c|c|c}
\hline $\begin{array}{c}\text { Type } \\
\text { of } \\
\text { Response }\end{array}$ & Class A & Class B & Class C \\
\cline { 2 - 4 } II & 9 & 18 & 7 \\
III & 2 & 3 & 2 \\
\hline
\end{tabular}

TABLE VII.-Relationship Between Type of Operation and Type

\begin{tabular}{c|c|c|c|c}
\hline $\begin{array}{c}\text { Type } \\
\text { of } \\
\text { Response }\end{array}$ & \multicolumn{4}{|c}{ Type of Operation } \\
\cline { 2 - 5 } & Abdominal & Herniorrhaphy & Varicose Veins & Others \\
\hline II & 13 & 16 & 2 & 3 \\
III & 2 & 2 & 1 & 3 \\
\hline
\end{tabular}

the operation the higher the incidence of type II and III, or the longer the operation the higher the incidence of type $I$.

TABLE VIII.-Relationship Between Length of Operation and Type of Response

\begin{tabular}{c|c|c}
\hline $\begin{array}{c}\text { Type } \\
\text { of } \\
\text { Response }\end{array}$ & \multicolumn{2}{|c}{ Length of Operation (Hours) } \\
\hline II & $0-1 z$ & $1 \frac{1}{2}-2 \frac{1}{2}$ \\
\hline III & 20 & 14 \\
2 & 5 & 2 \\
\hline
\end{tabular}

Anaesthetic Agents Used.-Although the drugs used are not tabulated in this paper their possible effects have been examined, and one point is worthy of mention. "Trilene" was used in six cases. Four of these showed a type II response. This is more than was expected and, in view of the cardiac-stimulating and adrenalinepotentiating effects of trilene, may be significant.

Immediate Post-operative Condition. - The four patients (Cases 11, 12,14, and 20) who were hypotensive after operation all developed the type IA response.

\section{Detailed Analysis of Type I Response}

A drop in calf blood flow occurred in $75.5 \%$ of the patients examined. In two-thirds of these the drop was present on the first day after operation, and in the rest it took a few days to develop.

Extent of Drop in Flow.-The average maximum drop in flow for all type I cases was $46.7 \%$. The average drop for type IA cases was $46.4 \%$ and for type IB cases $48.4 \%$. These figures do not give a true indication of the drop in flow likely to occur.

Fig. 6 shows two peaks, one at $30-39 \%$ and the other at $60-69 \%$; it is therefore likely that a patient will have a drop in flow of either $35 \%$ or $65 \%$ rather than one of the average value of $47 \%$.

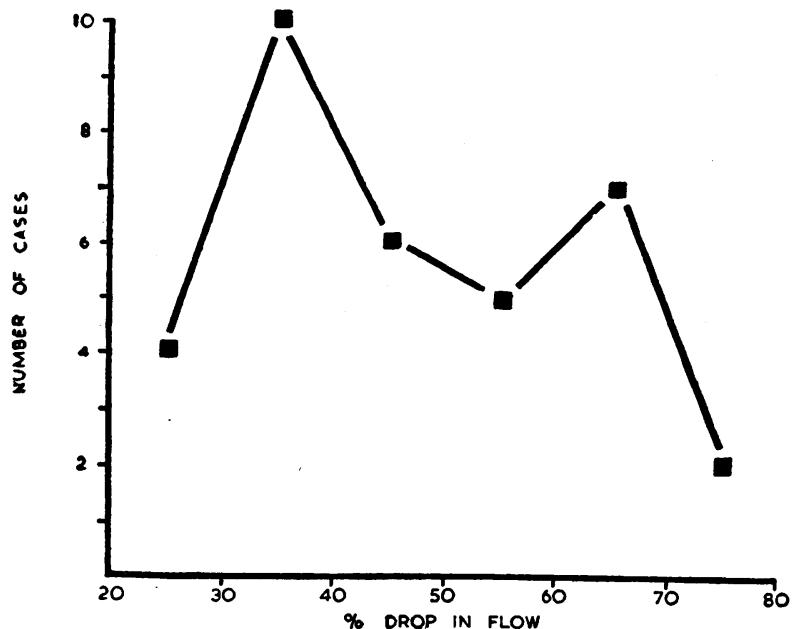

Fig. 6.-Distribution of the percentage drop in flow of all type cases.

Duration of Drop in Flow.-The average duration of the drop in flow-that is, that period during which the calf blood flow was less than the pre-operative levelwas eight days. The flow in the majority of type IA cases returned to normal by the eighth day (Table IX), but there was an appreciable number whose drop in flow lasted for 11 days or more. Does the depth of the drop in flow affect its duration? Table $\mathrm{X}$ indicates that the greater the drop in flow the longer it will last. 
Age and Depth of Drop.-Fig. 7 shows that the greater changes in flow are more common in elderly patients.

Age and Duration of Drop.-Table XI shows that the prolonged drops in flow occurred more often in old patients.

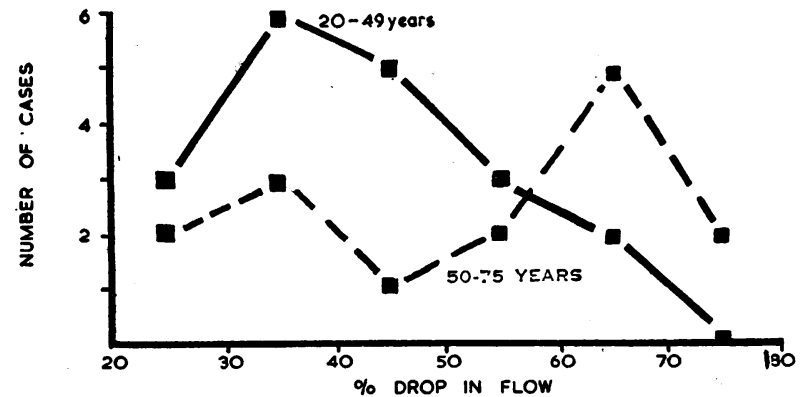

FIg. 7.--Relationship between age and depth of drop in flow.

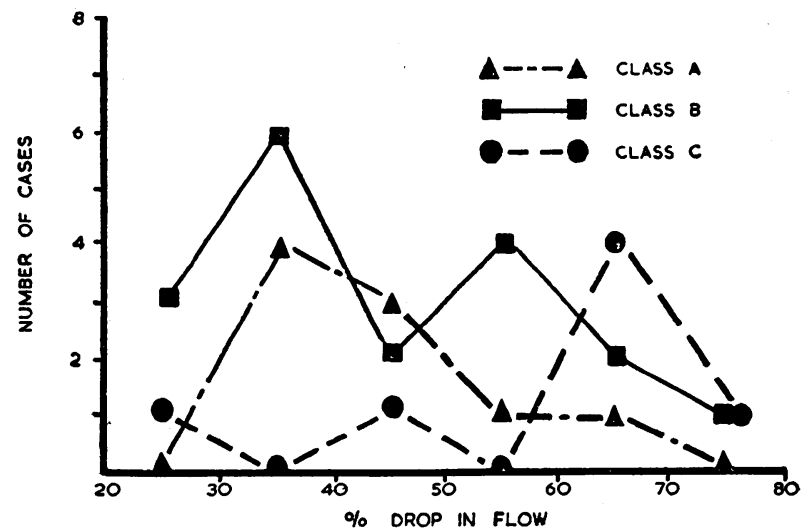

Fig. 8.-Relationship between fitness and depth of drop in flow.

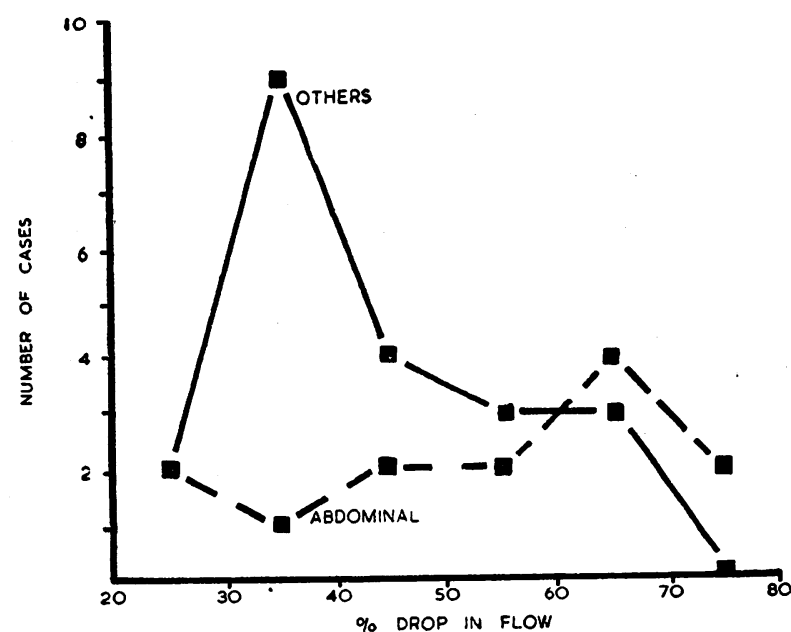

Fig. 9.-Relationship between type of operation and depth of drop in flow.

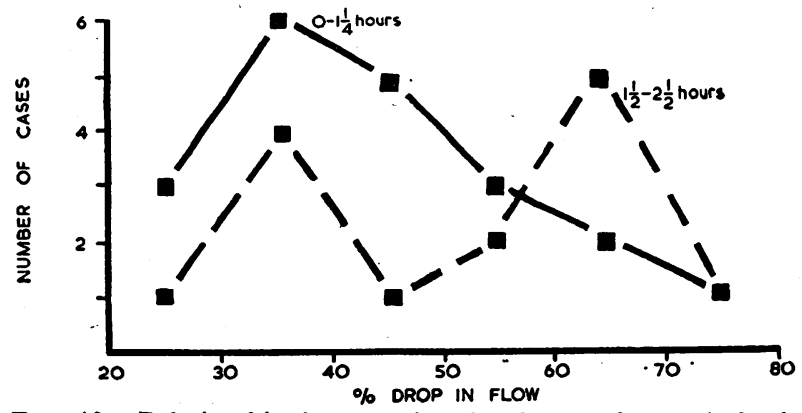

FIG. 10.-Relationship between length of operation and depth of drop in flow.
Fitness and Depth of Drop.-It is noticeable in Fig. 8 that most of the class A and B patients have drops of $30-39 \%$, whereas the majority of the ciass $C$ patients have $60-69 \%$ drops. It must be concluded that the patient's fitness does affect the depth of the drop in flow.

Fitness and Duration of Drop.-In Table XII only one-half of the class A patients have drops in flow lasting for six days or more, whereas this occurs in two-thirds of the class B subjects and four-fifths of class $C$.

Type of Operation and Depth of Drop.-Fig. 9 reveals that abdominal operations, the more traumatic surgically speaking, are more often followed by a deep drop in flow than the others.

Type of Operation and Duration of Drop.-The first column of Table XIII is striking, for it contains no abdominal cases. Whenever the type I response followed abdominal operations it lasted for six days or more.

Length of Operaition and Depth of Drop.-Fig. 10 demonstrates that the majority of those cases whose operation took less than $1 \frac{1}{2}$ hours had a drop in flow of $30-39 \%$. The longer operations have two peaks, but the greatest is at the $60-69 \%$ level. Fig. 10 is not the same as Fig. 9. A number of the lesser operation's took a long time to perform and quite a few of the major ones were completed within $1 \frac{1}{2}$ hours. Fig. 10, therefore, shows that the length of the operation affects the extent of the response irrespective of its severity.

TABLE IX.-Distribution of Duration of Drop in Flow (Group 1

\begin{tabular}{c|c|c|c|c|c|c|c|c|c}
\hline \multicolumn{1}{|c}{ Only) } \\
\hline \multirow{3}{*}{ Type } & \multicolumn{8}{|c}{ Duration of Drop (Days after Operation) } \\
\hline & 3 & 4 & 5 & 6 & 7 & 8 & 9 & 10 & $11+$ \\
\hline 1A & 1 & 2 & 1 & 4 & 1 & 2 & 1 & 1. & 5 \\
\hline
\end{tabular}

\begin{tabular}{|c|c|c|c|}
\hline \multirow{2}{*}{ Drop in Flow } & \multicolumn{3}{|c|}{ Duration of Drop (Days after Operation) } \\
\hline & 3-5 & 6-8 & $9-11+$ \\
\hline $\begin{array}{l}20-39 \% \\
40-59 \% \\
60-79 \%\end{array}$ & $\begin{array}{l}4 \\
3 \\
1\end{array}$ & $\begin{array}{l}2 \\
1 \\
4\end{array}$ & $\begin{array}{l}1 \\
4 \\
3\end{array}$ \\
\hline
\end{tabular}

TABLE XI.-Relationship Between Age and Duration of Drop (Group 1 Only)

\begin{tabular}{c|c|c|c}
\hline \multirow{3}{*}{ Age in Years } & \multicolumn{3}{|c}{ Duration of Drop (Days after Operation) } \\
\cline { 2 - 4 } & $3-5$ & $6-8$ & $9-11+$ \\
\hline $20-49$ & 5 & 3 & 3 \\
$50-75$ & 3 & 4 & 5 \\
\hline
\end{tabular}

TABLE XII.-Relationship Between Fitness and Duration of Drop

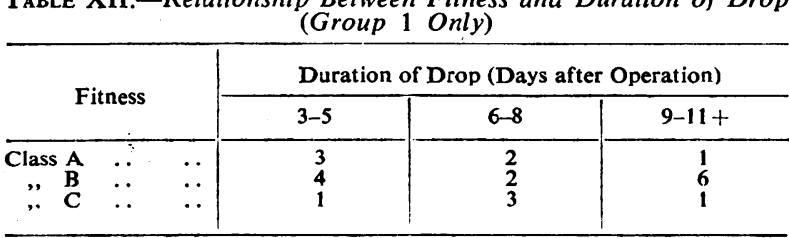

TABLE XIII.-Relationship Between Type of Operation and

\begin{tabular}{|c|c|c|c|}
\hline \multirow{2}{*}{ Type of Operation } & \multicolumn{3}{|c|}{ Duration of Drop (Days after Operation) } \\
\hline & $3-5$ & 6-8 & $9-11+$ \\
\hline $\begin{array}{l}\text { Others } \\
\text { Abdominai }\end{array}$ & $\begin{array}{l}8 \\
0\end{array}$ & $\begin{array}{l}2 \\
5\end{array}$ & $\begin{array}{l}3 \\
5\end{array}$ \\
\hline
\end{tabular}


Length of Operation and Duration of Drop.-The diminishing numbers in the short operation line of Table XIV and the increasing numbers in the long imply that the longer the operation the more likely is the drop in flow to be prolonged beyond 6-8 days.

TABLE XIV.-Relationship Between Length of Operation and Duration of Drop (Group 1 Only)

\begin{tabular}{l|c|c|c|c}
\hline \multirow{2}{*}{ Length of Operation } & \multicolumn{2}{|c|}{ Duration of Drop (Days after Operation) } \\
\cline { 2 - 4 } & & $3-5$ & $6-8$ & $9-11+$ \\
\hline $0-1 \frac{1}{2}$ hours & $\cdots$ & 7 & 5 & 3 \\
$1 \frac{1}{2}-2 \frac{1}{2}, "$ & 1 & 2 & 5 \\
\hline
\end{tabular}

Anaesthetic Agents and Type I Response.-It has already been noted that four of the six cases given trilene developed the type II response. The two that showed a drop in flow (Cases 25 and 33) had drops of $26 \%$ and $36 \%$-both much less than the overall average.

Immediate Post-operative Condition.-The four cases causing concern after operation all had the type IA response. Their average drop in flow was $61 \%-14 \%$ more than the overall average value.

Post-operative Activity and Duration of Drop.Fig. 11 shows that post-operative activity has no effect upon the duration of the response. In only one case does the day of return to full ambulation coincide with the day on which the blood flow returned to normal. In six cases the flow was back to normal before the patient was fully ambulant, but 16 cases continued to have a diminished resting calf blood flow despite being fully ambulant.

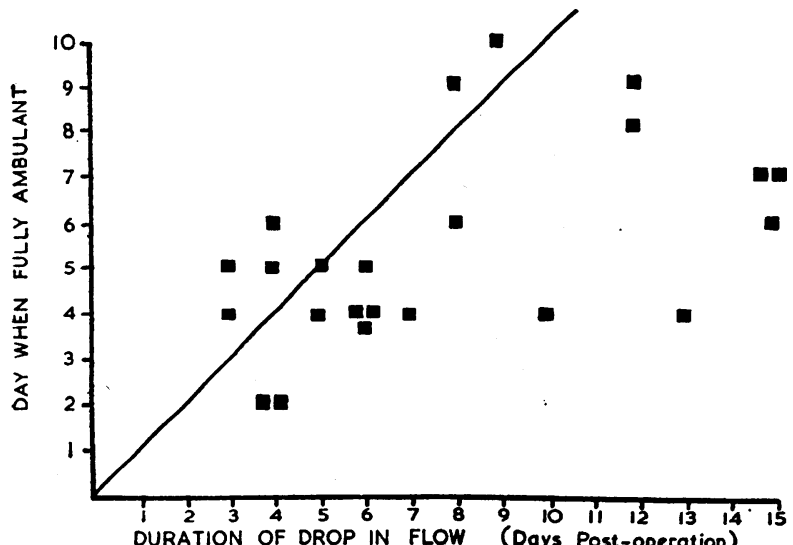

FIG. 11.-Relationship between post-operative activity and duration of drop in flow (group 1 only).

\section{Analysis of Type II Response}

The type II response occurred in $15.5 \%$ of the patients studied. All but one had the IIA response. The IIB response was the least common of all.

Extent of Rise in Flow.-The average maximum increase in flow for all type II cases was $78.5 \%$. The average maximum increase in flow for type IIA cases was $82 \%$. The rise in the type IIB case was $56 \%$. These average figures are drawn from a wide range. The largest rise observed was $166 \%$ and the smallest $43 \%$.

Duration of Rise in Flow (Group 1 only).-The average duration of increased flow was five days. Individually, the increases in flow lasted for $3,9,6$, and 3 days. No positive relationship can be found between the height of the rise and its duration.

The relationships between the nature of the response and the patient's age, fitness, type and length of operation, and post-operative activity have been studied in exactly the same way as the type I response. The tables are not presented, because they do not show any positive facts apart from indicating that abdominal operations are followed by bigger rises in flow.

That no definite relationships can be demonstrated should not be taken as positive evidence of absence of them, because the number of patients is too small for analysis (seven in all, only four in group 1).

\section{Analysis of Type III Response}

Four cases showed the type III response. The averäge rise in flow was $92 \%$ and the drop $39.5 \%$. The increased flow lasted, on average, for two days and the drop in flow from the second to the seventh day. Every possible interrelationship has been examined. Conclusions drawn from observations on only four patients cannot be conclusive, but certain positive points are worth mentioning.

There is a suggestion that the higher the initial rise in flow the smaller the subsequent drop.

The greater the rise in flow the longer it lasts.

All four patients were in late middle age- $63,53,51$, and 66 years-and all were of class B fitness. None had had an abdominal operation.

\section{Control Studies}

Four things happen to a patient when he undergoes an operation. (1) $\mathrm{He}$ changes his way of life to the routine of the ward, wherein he spends $60 \%$ of every 24 hours in bed. (2) From shortly before, during, and for three to four days after his operation he is confined to bed. (3) He has a general anaesthetic. (4) He has a surgical operation.

Each of these factors may have been responsible for the changes in blood flow that have been observed. Each required investigation in its own right. Because the studies of the effect of bed rest proved to be both interesting and unexpected they have been made the subject of a separate article (Browse, 1962).

1. Effect of Ward Life.-It was found that in healthy male patients living the routine ward life the resting calf blood flow, measured daily, did not change. Furthermore, the resting flow measured immediately after admission to hospital, when it could be assumed that it was the level that existed during the patients' normal life, was no greater than the resting flow measured 3, 5 , 7 , or 9 days later. The resting calf blood flow is therefore extremely stable and not affected by changes in the amount of exercise performed each day.

2. Effect of Bed Rest Alone.-Seventeen patients were studied. It was found that the calf blood flow reached its basal level before an hour of rest had elapsed and that further complete rest for as long as five days had no effect upon it.

3. Effect of General Anaesthesia Alone.-The changes that occur in the blood flow to muscles during general anaesthesia have been studied by a number of workers (Lee et al., 1953 ; Kitchen et al., 1953). The object of the present study was to see if anaesthesia had any effect on muscle blood flow that persisted into the postoperative period after consciousness had returned. Only two patients were studied (Cases 59 and 60), for when examining these patients a few hours after their anaesthetic it was obvious that they were perfectly fit and without any after-effects, and this impression 
was confirmed by finding their resting calf blood flows unchanged. The conclusion is that once the effect of the anaesthetic drugs has worn off it is illogical to expect them to have any continued influence upon the muscle blood flow.

Case 59.-Male clerk aged 60 . No previous illness. Class B fitness. Admitted for sigmoidoscopy in view of a change in bowel habit for six months. (Anaesthetic: thiopentone, fluothane, oxygen, nitrous oxide.) The calf blood flows were as shown in the following Table.

\begin{tabular}{|c|c|c|}
\hline Day & Activity & $\begin{array}{l}\text { Blood Flow } \\
\text { (ml. } \text { min. }, 100 \mathrm{ml} \text { ) }\end{array}$ \\
\hline $\begin{array}{r}-2 \\
-1 \\
-0 \\
+1 \\
2 \\
3 \\
4 \\
5 \\
6\end{array}$ & $\begin{array}{l}\text { Fully ambulant } \\
\text { In bed for only } 3 \text { hours } \\
\text { Fully ambulant } \\
\text { ", ", } \\
\text { ", ", } \\
\text { ", ", }\end{array}$ & $\begin{array}{l}1.7 \\
1.8 \\
1.7 \\
1.8 \\
1.9 \\
1.7 \\
1.9 \\
1.8\end{array}$ \\
\hline
\end{tabular}

Case 60.-Male clerk aged 40. No previous illnesses until an attack of haematuria. Class B fitness. Admitted for cystoscopy. The calf blood flows are shown in the following Table.

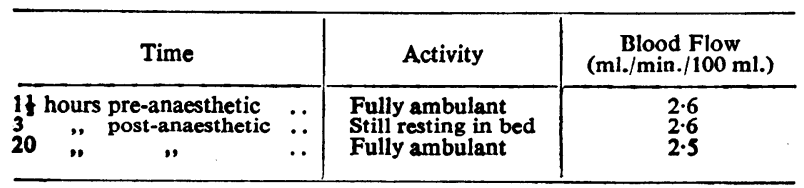

4. Surgical Operations without General Anaesthesia. -It was impossible to examine the effect of surgery performed without any form of anaesthesia, but the effect of a general anaesthetic was excluded by studying cases where surgery had been performed under local anaesthesia. Only two cases were examined once it was found that they both showed the type I response.

Case 43.-Man aged 42. Class $C$ fitness (chronic bronchitis). Loss of weight for six months due to a benign pyloric stenosis. Partial gastrectomy was performed under an epidural block produced by $38 \mathrm{ml}$. of $1.2 \%$ lignocaine. This patient showed a type IA response to surgery with a $25 \%$ drop in calf blood flow that lasted for six days (Tables II, III, and IV).

Case 45.-Youth aged 17. Class A fitness. Bilateral inguinal herniae. Both herniae were repaired at one session using a local infiltration of $1 \%$ procaine hydrochloride. This patient showed a type IA response with a drop in flow of $35 \%$ that lasted for four days (Tables II, III, and IV).

Both these patients were young and would be expected to show changes of flow in the $30 \%$ range rather than in the 60 s.

\section{Discussion}

From the analyses presented it would appear that:

1. $75 \%$ of patients undergoing surgical operations have a 50\% drop in calf blood flow lasting 4-14 days. The remainder show either an increase in flow or a rise followed by a fall. (No patient has yet failed to exhibit one of the five types of response described.)

2. Two factors may influence the type of response that develops. First, long operations seem more likely to induce the type I response. Secondly, trilene, when used for anaesthesia, may increase the incidence of the type II response. Doth these conclusions are made on poor evidence. Neither miay be correct.

3. The type I response is definitely affected, both in extent and in duration, by the age and fitness of the patient and by the length and severity of the operation. Post-operative activity has no effect on the response.

Every patient can be said to show "a circulatory response to surgery."

If no factor affects the nature of the response then it can be said that it is an inherent property of the individual. If it is affected by outside factors-and there is the suggestion that length of operation and trilene may do so-one must deduce that each patient has within him the ability to develop any of the five responses. As all the main characteristics of the patient and his operation undoubtedly affected the degree of the response and only two may have affected its nature, it is probable that the former deduction is correct and that the response is a basic characteristic of the subject. This can be proved by finding the same type of response in the same patient after different operations at different ages. (One patient, not included here, has been studied through two operations, and both times she showed a IA response with a $25 \%$ drop in flow.)

It may be argued that such conclusions should not be drawn from measurements made with such a relatively crude machine as the plethysmograph. The constancy of the control studies and of the control readings of each patient taken before operation shows that the technique is more accurate than is generally acknowledged and that the changes observed are both real and significant.

Have these studies any clinical value ? One cannot help but think that the type I change in flow is connected with post-operative deep-vein thrombosis. It would be wrong to jump to any conclusions at this stage. If it can be shown that the incidence of thrombosis is reduced by abolishing the type I response, then it would be acceptable to say that the type I change is a factor of importance. Research so far has failed to find any drug that will alter the type I response.

The type I change is unlikely to be beneficial to the patient. The analysis has shown that the longer an operation lasts the deeper is the drop in flow. It behoves surgeons, therefore, to keep operations as short as possible. This is not a plea for hurried surgery, but at the same time the common attitude of "the length of the operation does not matter now that we have modern anaesthesia " is to be deplored and contradicted whenever possible.

The failure of post-operative activity to influence the resting calf blood flow is very noticeable. Many patients are forced out of bed on their first day after operation and made to walk about because the surgeon believes he is stimulating the circulation and so repelling incipient deep-vein thrombosis. Clinically, early ambulation has long been shown not to have any effect upon the incidence of deep-vein thrombosis (Blodgett and Beattie, 1946 ; Powers, 1947). These studies show why.

Early activity and ambulation is good for the patient's morale, his pressure points, and his lungs, and should be encouraged for these reasons, not for false ones.

\section{Summary and Conclusions}

The resting calf blood flow has been measured daily in a group of 45 patients undergoing routine surgical operations.

The resting calf blood flow, mainly a measure of muscle blood flow, showed five different types of change. These changes have been called the "circulatory 
response to surgery, types IA and IB, IIA and IIB, and III." They are defined.

A fall in blood flow (type I) occurred in $75.5 \%$ $53.3 \%$ immediately (IA) and $22.2 \%$ gradually (IB). The average drop in flow was to a level $47 \%$ below the pre-operative level and lasted for eight days. Drops in flow of $70-80 \%$ were encountered.

The remainder showed either a rise in flow $(15.5 \%$, type II) or a rise followed by a fall ( $9 \%$, type III).

The extent and duration of the drop in flow was affected by the patient's age and fitness, and by the severity and length of his operation.

Control studies show that $(a)$ the resting calf blood flow is remarkably constant from day to day in a patient living the normal ward life, $(b)$ it is unaffected by long periods of bed rest, $(c)$ it is unchanged after a general anaesthetic alone, and $(d)$ the changes of flow that follow operations performed under general anaesthesia also occur after operations performed under local anaesthesia.

The unavoidable conclusion is that the changes in blood flow observed are a result of the surgical trauma alone. Bed rest and general anaesthesia are blameless. The aetiology of these changes is not yet known.

I thank Professor R. Milnes Walker and Mr. J. H. Peacock for their help and encouragement, and all the patients who co-operated with me, often on the day after a major operation, when they were feeling wretched.

The experiments in this paper are the basis of a thesis submitted to the University of Bristol for the degree of Doctor of Medicine.

\section{REFERENCES}

Barcroft, H., and Swann, H. J. C. (1953), Sympathetic Control of Human Blood Vessels. Arnold, London.

Blodgett, J. B., and Beattie, E. J. (1946). Surg. Gynec. Obstet., 82,485 .

Browse, N. L. (1961). M.D. Thesis, Univ. of Bristol.

- (1962). Brit. med. J., 1. 1721.

Grant, R. T., and Pearson, R. S. B. (1937). Clin. Sci., 3, 119.

Kitchen, A. H., Sanger, C., De Wardener, H. E., and Young, I. M. (1953). Ibid., 12, 361 .

Lee, G. de J., Churchill-Davidson, H., Miles, B. E., and De Wardener, H. E. (1953). Ibid., 12, 169.

Powers, J. H. (1947). Amer. J. Med., 3, 224.

Smith, L. A., and Allen, E. V. (1940). Arch. Surg., 41, 1377.

Wright, H. P., Osborn, S. B., and Edmonds, D. G. (1948). Lancet, 2, 767.

\title{
EFFECT OF BED REST ON RESTING CALF BLOOD FLOW OF HEALTHY ADULT MALES
}

\author{
BY \\ N. L. BROWSE, M.D., F.R.C.S. \\ Department of Surgery, University of Bristol*
}

Rest in bed is an integral part of practically all medical and surgical treatment, yet it is not without risk. Pressure ulcers and hypostatic pneumonia are two common complications, deep-vein thrombosis and pulmonary embolism may be others. It is surprising that the scientific journals contain so few papers on the physiological effects of bed rest. This paper is concerned with the effect of long periods of bed rest upon the muscle blood flow of the calf.

\section{Subjects}

Twenty-nine patients have been studied. In a busy hospital it is difficult to find healthy men whom one can confine to bed for the purposes of research. There is, however, a steady stream of fit men coming into hospital for operations on their hernias, haemorrhoids, ulcers, etc., who sometimes have to wait three or four days for their operation. Such patients formed the main group of subjects for this study. Others were men awaiting investigations-for example, urograms, barium studies, and endoscopies.

All 29 were healthy adult males. That is to say, their complaint was in no way affecting their general health and they were all capable of a full day's hard work. None had any detectable cardiac, pulmonary, or malignant disease.

The series contains men of all ages: two in their 'teens, six in their twenties, five in their thirties, four in their forties, six in their fifties, and six in their sixties-a fairly even distribution in spite of the fact that selection for this study, with the exception of the standard of fitness required, was a matter of chance.

\section{Technique}

Method of Measuring the Calf Blood Flow

The calf blood flow was measured with a venousocclusion plethysmograph. The plethysmograph was applied with the patient in the "resting state" (see below) in his own bed in the ward. It was filled with water kept at a temperature of $34^{\circ} \mathrm{C}$. The patient was left with his leg in the apparatus for half an hour before any measurements were taken, in order to allow his skin blood flow to adjust itself to the temperature of the water. Venous occlusion was obtained with a collecting pressure, $10 \mathrm{~mm}$. $\mathrm{Hg}$ below the patient's diastolic blood-pressure, applied through an inflatable cuff above the knee.

A second cuff was placed round the leg immediately beyond the plethysmograph and inflated at the same time as the collecting cuff to the same pressure. This, and the environmental conditions, were the only differences from the technique of plethysmography described by Barcroft and Swann (1953). They applied a pressure of $200 \mathrm{~mm}$. Hg to the cuff below the plethysmograph in order to exclude the foot completely from the circulation of the limb. It was felt that this technique must affect the circulation higher up the limb, and it was thought sufficient-the environmental temperature (and so the temperature of the skin of the skin of the foot) being fairly constant-simply to exclude the venous return of the foot from the plethysmograph during the period of venous occlusion. Furthermore, the total period of recording lasted 15 to 20 minutes, and total circulatory occlusion for this length of time was extremely uncomfortable. Intermittent complete occlusion was not possible because the reactive hyperaemia it induced vitiated the recording.

Two sets of 10 to 20 periods of venous occlusions were recorded with a 10-minute pause between each set. Venous occlusion was applied for 5 to 10 seconds and followed by a 30-second pause.

Theoretical calculations and practical tests showed the maximum experimental error to be approximately

*Now Lecturer in Surgery, Westminster Hospital. 